\title{
Biodegradation testing of chemicals with high Henry's constants - Separating mass and effective concentration reveals higher rate constants
}

Birch, Heidi; Andersen, Henrik Rasmus; Comber, Mike; Mayer, Philipp

Published in:

Chemosphere

Link to article, DOI:

10.1016/j.chemosphere.2017.02.003

Publication date:

2017

Document Version

Peer reviewed version

Link back to DTU Orbit

Citation (APA):

Birch, H., Andersen, H. R., Comber, M., \& Mayer, P. (2017). Biodegradation testing of chemicals with high Henry's constants - Separating mass and effective concentration reveals higher rate constants. Chemosphere, 174, 716-721. https://doi.org/10.1016/j.chemosphere.2017.02.003

\section{General rights}

Copyright and moral rights for the publications made accessible in the public portal are retained by the authors and/or other copyright owners and it is a condition of accessing publications that users recognise and abide by the legal requirements associated with these rights.

- Users may download and print one copy of any publication from the public portal for the purpose of private study or research.

- You may not further distribute the material or use it for any profit-making activity or commercial gain

- You may freely distribute the URL identifying the publication in the public portal 
2 Henry's Constants - Separating Mass and Effective

\section{Concentration Reveals Higher Rate Constants}

5 Technical University of Denmark, Department of Environmental Engineering, Bygningstorvet, Building 115, 2800 Kgs. Lyngby, Denmark. hbir@env.dtu.dk, hran@env.dtu.dk,

11 Heidi Birch, Technical University of Denmark, Department of Environmental Engineering,

12 Building 115, 2800 Kgs. Lyngby, Denmark, hbir@env.dtu.dk, +45 45251600. 


\section{Abstract}

15 During simulation-type biodegradation tests, volatile chemicals will continuously partition

16 between water phase and headspace. This study addressed how (1) this partitioning affects test

17 results and (2) can be accounted for by combining equilibrium partition and dynamic

18 biodegradation models. An aqueous mixture of 9 (semi)volatile chemicals was first generated

19 using passive dosing and then diluted with environmental surface water producing

20 concentrations in the $\mathrm{ng} / \mathrm{L}$ to $\mu \mathrm{g} / \mathrm{L}$ range. After incubation for 2 hours to 4 weeks, automated

21 Headspace Solid Phase Microextraction (HS-SPME) was applied directly on the test systems to

22 measure substrate depletion by biodegradation relatively to abiotic controls. HS-SPME was also

23 applied to determine air to water partitioning ratios. Biodegradation rate constants relating to the

24 chemical in the water phase, $\mathrm{k}_{\mathrm{water}}$, were generally a factor 1 to 11 times higher than

25 biodegradation rate constants relating to the total mass of chemical in the test system, $\mathrm{k}_{\text {system, }}$

26 with one exceptional factor of 72 times for a long chain alkane. True water phase degradation

27 rate constants were found (i) more appropriate for risk assessment than test system rate

28 constants, (ii) to facilitate extrapolation to other air-water systems and (iii) to be better defined

29 input parameters for aquatic exposure and fate models.

Table of Contents Graphics:
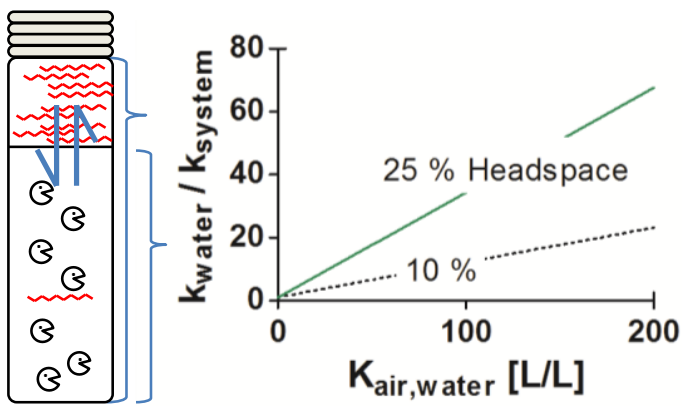
32 Keywords: Biodegradation test, volatile chemicals, hydrocarbon, rate constant, headspace

\section{Introduction}

34 Biodegradation is an important environmental fate process for most organic chemicals, and 35 data describing biodegradation kinetics are thus needed for modelling and risk assessment

36 purposes (Aronson et al., 2006). Outside of the regulatory systems, estimation of kinetic

37 degradation data from screening test data (Aronson et al., 2006) or via quantitative structure

38 relationships has been attempted (Howard et al., 2005), however good quality kinetic data from

39 laboratory based tests or field studies are called for (Aronson et al., 2006; Gouin et al., 2004).

40 Within the regulatory system biodegradability testing is required under the Registration,

41 Evaluation, Authorisation and Restriction of Chemicals legislation in the European Union

42 (European Parliament, 2006) and Toxic Substances Control Act in the United States (US Public

43 law, 2002). At the screening level of environmental risk assessment or assessment of persistence,

44 bioaccumulation and toxicity, the Ready Biodegradation studies, OECD series 301 (OECD,

45 1992), are used. They include test methods without a headspace, which are appropriate for

46 volatile chemicals, but are often conducted at very high test substance concentrations. These

47 measure ultimate biodegradation on a pass/fail level. Half-lives or rate constants are assigned

48 based on whether, or not, the chemical is assessed as Readily Biodegradable. Subsequent

49 evaluations may require further assessment through simulation biodegradation studies that can

50 deliver primary biodegradation half-lives or rate constants. Unfortunately, these methods are

51 generally categorized as not applicable to volatile chemicals.

52 The first step of adapting test systems for volatile chemicals with high air to water partition

53 ratios (i.e. Henry's constants) is a closed test design, which circumvents evaporative losses out of

54 the test system. When testing chemicals at low concentrations, the dissolved oxygen in the 
55 environmental sample is sufficient for the degradation of the test chemicals, however,

56 environmental samples contain natural organic matter which also consumes oxygen, and

57 therefore a headspace can be needed to ensure aerobic conditions. A major fraction of volatile

58 chemicals, will then reside in the headspace. During the degradation phase, partitioning between

59 water phase and headspace will govern the distribution of chemicals in the test system,

60 continuously replenishing the test chemicals degraded in the water phase. For volatile

61 substances, there is then a mismatch between the effective concentration for the biodegradation

62 in the water phase and the total mass distributed between water and headspace. In unsaturated

63 soil, researchers have addressed the importance of the vapor phase as a reservoir and mass-

64 transfer medium for volatile chemicals (Khan et al., 2016). However, in environmental surface

65 water systems, volatilization would mostly act as a sink rather than a buffer for volatile

66 chemicals, and therefore the water phase biodegradation is the relevant parameter when

67 extrapolating to other test or environmental surface water systems.

68 The fact that the dissolved concentration rather than the total mass of test chemical may govern

69 biodegradation rates has been realized earlier, especially for highly sorbing chemicals in test

70 systems including sediments and soils (Reichenberg and Mayer, 2006). Monod kinetic

71 parameters have in some cases been determined using sets of non-linear differential equations

72 describing degradation and the distribution or rates of transfer between the air/water phase and

73 unsaturated soil (Höhener et al., 2003; Ostendorf et al., 2007; Rein et al., 2007; Sleep and

74 Mulcahy, 1998), soil-slurry (Woo et al., 2001), test vessel (Guha and Jaffé, 1996) or

75 microcrystals (Adam et al., 2014). These studies employed quite extensive modeling efforts,

76 which are not usually employed in legislative biodegradation testing. 
77 Schirmer et al. (1999) suggested a simple approach assuming instantaneous partitioning

78 between phases and describing the distribution in the test system by a mass distribution

79 coefficient, defined as the ratio of the total mass in the test system to the bioavailable mass at

80 equilibrium. A mass distribution coefficient of 1.86 was determined for $m$-xylene in their study

81 (Schirmer et al., 1999). Later studies (Comber et al., 2012; Prince et al., 2008, 2007), using more

82 volatile chemicals, did not take distribution to headspace into account, and thus biodegradation

83 rates were likely underestimated.

84 The present study investigated the primary biodegradation of a mixture of 9 (semi)volatile

85 chemicals in surface water. The chemicals were selected to cover different chemical structures of

86 potential oil constituents (see Table 1), and the testing was conducted at low aqueous

87 concentrations (ng/L $-\mu \mathrm{g} / \mathrm{L}$ range) in order to obtain biodegradation results of high

88 environmental relevance. We investigated (1) how partitioning between water phase and

89 headspace affects test results and (2) how partitioning can be accounted for by combining an

90 equilibrium partition model with a first order or logistic biodegradation model. The present study

91 introduces a new experimental framework, where phase partitioning of the test chemicals was

92 applied for the (i) conduct, (ii) analytical measurements and (iii) the assessment of the

93 biodegradation tests: (i) Phase partitioning from a loaded silicone rod was used to generate

94 defined composed mixtures of hydrocarbons at the beginning of the experiments. (ii) Phase

95 partitioning into a thin silicone coating was the basis for the automated sampling directly in the

96 test systems at the end of the experiment. (iii) Finally, the phase partitioning of the test

97 substances between water and headspace was measured and then applied to distinguish the

98 biodegradation kinetics in the test system (water and headspace) and the biodegradation kinetics

99 in the water phase. The experimental and analytical procedure was designed to obtain very 
100 accurate and precise "relative concentrations", as input for fitting the biodegradation kinetic

101 model. This was obtained by incubation of test systems in gas tight $20 \mathrm{~mL}$ autosampler vials,

102 which at the end of the experiment were measured directly by automated Headspace Solid Phase

103 Microextraction, and by normalizing the Gas Chromatograpy (GC) response by measurements of

104 abiotic control vials which had been incubated together with the samples and measured within

105 the same analytical series.

106

$107 \quad 2$ Theory

108 Monod kinetics can be used to describe biomass growth on a single substrate (Simkins and

109 Alexander, 1984). In a system including headspace, we propose to separate the total mass of the

110 test substance in the test system $\left(m_{T}\right)$ from the concentration in the water phase $\left(C_{w}\right)$ determining

111 the biodegradation rate, realizing that degradation takes place in the water phase.

112 At low substrate concentration (ng/L - $\mu \mathrm{g} / \mathrm{L}$ range) and low initial biomass, monod based

113 degradation kinetics can be simplified by the Logistic model (Simkins and Alexander, 1984),

114 shown in Equation 1 for a test system with headspace.

115

(1) $\frac{d m_{T}}{d t}=-a_{w a t e r} V_{w} C_{w}\left(C_{w, 0}+X_{0}-C_{w}\right)$

$116 X_{0}$ is the initial specific degrader population density divided by the yield (i.e. the amount of

117 chemical needed to produce the initial specific degrader population density), $a$ is the logistic rate

118 constant, $K_{S}$ is the half-saturation constant for growth of the degrading organisms and it is

119 assumed that $C_{w, 0}<<K_{S}$.

120 For practical/regulatory purposes, this model is often approximated by a lag phase, $t_{\text {lag }}$, (during

121 which biomass adapts/increases but no degradation takes place) followed by first order 122 degradation (e.g. OECD 309, 2004). 
123 The first order degradation after the lag phase in systems with a headspace is therefore 124 described by equation 2 .

125 (2) $\frac{d m_{T}}{d t}=-k_{\text {water }} V_{w} C_{w}$

126 Where $k_{\text {water }}$ is the rate constant in the water phase and $V_{w}$ is the volume of the water phase.

127 The distribution between water phase and headspace is governed by equilibrium partitioning.

128 If the partitioning rates are faster than the degradation rate, the ratio $m_{w} / m_{T}$ can be assumed 129 constant during the test, and equation 2 can be converted to equation 3 and solved for $C_{w}$ from $\mathrm{t}$ $130=0$ to $\mathrm{t}=\infty$ (equation 4 ). (3) $\frac{d C_{w}}{d t}=-k_{w a t e r} \frac{m_{w, 0}}{m_{T, 0}} C_{w}$ (4) $C_{w}=C_{w, 0} e^{-k_{w a t e r} \frac{m_{w, 0}}{m_{T, 0}}\left(t-t_{\text {lag }}\right)}$

133 where $m_{w, 0}$ and $C_{w, 0}$ is the initial mass and concentration of the test chemical in the water phase 134 and $m_{T, 0}$ is the initial total mass of the test chemical.

135 Fitting a first order model to data without taking distribution in the test system into account 136 yields the test system first order rate constant, $k_{\text {system }}$, which relates to the water phase rate 137 constant by equation 5 .

(5) $k_{\text {system }}=k_{\text {water }} \frac{m_{w, 0}}{m_{T, 0}}=k_{\text {water }} \cdot \frac{V_{w}}{V_{w}+K_{a w} V_{h}}$

139 where $V_{h}$ is the volume of the headspace, $V_{w}$ is the volume of the water phase, and $K_{a w}$ is the air 140 water partition ratio for the test chemical. Water phase degradation rate constants for chemicals 141 with high air to water partition ratios are thus higher than test system rate constants, and half142 lives are lower in the water phase than in the test system.

143 For some research purposes, the Monod based logistic model is preferred to the first order 144 degradation model because this model uses descriptors relating to biological processes. 
145 However, the same principle can be used with this model, and the relationship between the test

146 system logistic rate constant $\left(a_{\text {system }}\right)$ and the water phase logistic rate constant $\left(a_{\text {water }}\right)$ similarly

147 depends on the fraction of test chemical in the water phase compared to the total mass in the test

148 system (see equation 6 and Supporting Information S1)

149

(6) $a_{\text {system }}=a_{\text {water }} \frac{m_{w, 0}}{m_{T, 0}}=a_{\text {water }} \cdot \frac{V_{w}}{V_{w}+K_{a w} V_{h}}$

\section{Materials and Methods}

\subsection{Materials}

153 The test chemicals (purity of $\geq 98 \%$ ) were $n$-decane, tetralin, biphenyl, trans-decalin, 154 bicyclohexyl, 1,2,4-trimethylbenzene, naphthalene (Sigma-Aldrich, Copenhagen, Denmark), 2,3155 dimethylheptane and 1,3,5-trimethylcyclohexane (Tokyo Chemical Industry Europe, 156 Zwijndrecht, Belgium). 1-octanol (Sigma-Aldrich) was used as reference chemical. Translucent 157 silicone rod (diameter $3 \mathrm{~mm}$; custom-made by Altecweb.com, product code 136-8380) was used 158 as partitioning donor for the passive dosing. Its partitioning properties have recently been 159 referenced against other silicones that are used for passive sampling and dosing (Gilbert et al, 160 Anal Chem, 2016). Ethylacetate ( $\geq$ 99.7\%, Sigma-Aldrich) and ethanol ( $>99.8 \%$, VWR 161 chemicals) were used for pre-cleaning of the silicone rods. Ultrapure water was produced on a 162 LaboStar $^{\mathrm{TM}}$ 1-DI ultrapure water system from SGwater (Hamburg, Germany).

\section{$163 \quad 3.2$ Preparation of stock solution by passive dosing}

164 Pre-cleaned silicone rods were loaded by addition of an equi-mass mixture $(1: 1: 1 \ldots)$ of nine 165 neat test chemicals that were quantitatively absorbed by the rods. An aqueous stock solution was 166 then generated by passive dosing from these loaded rods. The stock solution was subsequently 167 diluted 10 fold resulting in initial test substance concentrations 2-4 orders of magnitude below 
168 the solubility of each test substance. Later measurements of concentrations produced by the

169 silicone rods revealed initial test concentration levels of approximately $0.03 \mu \mathrm{g} / \mathrm{L}$ bicyclohexyl,

$17030 \mu \mathrm{g} / \mathrm{L}$ biphenyl, $0.5 \mu \mathrm{g} / \mathrm{L}$ decalin, $0.2 \mu \mathrm{g} / \mathrm{L} n$-decane, $0.2 \mu \mathrm{g} / \mathrm{L}$ 2,3-dimethylheptane, $70 \mu \mathrm{g} / \mathrm{L}$

171 naphthalene, $30 \mu \mathrm{g} / \mathrm{L}$ tetralin, $60 \mu \mathrm{g} / \mathrm{L}$ 1,2,4-trimethylbenzene and $0.5 \mu \mathrm{g} / \mathrm{L} \quad 1,3,5-$

172 trimethylcyclohexane. All transfer of stock solution was done using gas tight syringes. See

173 Supporting Information S2 for details.

$174 \quad 3.3$ Surface water inoculum

175 A surface water grab sample was taken from a small brook (Fønstrup Brook) in northern

176 Sealand, Denmark, which runs through forest, and is not pre-adapted to petroleum hydrocarbons

177 by stormwater or wastewater discharges. The samples contained no measurable background

178 concentrations of the test chemicals. Heterotrophic Plate Count measurements yielded a bacterial 179 count of $1.2 \cdot 10^{4}$ colony forming units $/ \mathrm{mL}$.

$180 \quad 3.4$ Biodegradation test method

181 Biodegradation test systems were prepared in $20 \mathrm{~mL}$ headspace vials with PTFE faced silicone

182 septa compatible with the GC autosampler. $13.5 \mathrm{~mL}$ of unfiltered surface water, spiked with 30

$183 \mu \mathrm{g} / \mathrm{L}$ 1-octanol, was added to all biotic test system vials. $1.5 \mathrm{~mL}$ stock solution was then added,

184 bringing the total water volume to $15 \mathrm{~mL}$, and the vials were closed immediately. Abiotic test

185 systems were prepared in the same way using ultrapure water instead of surface water. Test 186 systems were incubated at $20^{\circ} \mathrm{C}$ on a roller mixer $(\sim 30 \mathrm{rpm})$. On day $0,1,2,5,6,8,10,14,20$

187 and 27, three biotic and three abiotic test systems were harvested for analysis.

\section{$188 \quad 3.5$ Phase distribution tests}

189 Varying the headspace to water phase ratio in test systems, can reveal the air to water partition 190 ratio (Mayer et al., 2000). Stock solution was added to $20 \mathrm{~mL}$ vials in volumes of 2.5, 5, 15, 17 
191 and $19 \mathrm{~mL}$ in triplicate. After equilibration by 5 minutes shaking on a vibrax orbital shaker at $1921000 \mathrm{rpm}, 2 \mathrm{~mL}$ of the water phase was transferred to $20 \mathrm{~mL}$ vials. $2 \mathrm{~mL}$ of the stock solution 193 was also transferred directly to three $20 \mathrm{~mL}$ vials.

$194 \quad 3.6$ Analytical method

195 Analysis was done by Gas Chromatography - Mass Spectrometry using fully automated 196 Headspace Solid Phase Micro Extraction directly in test vials (See Supporting Information S3 for 197 details).

$198 \quad 3.7$ Data treatment

199 The analytical response in the test systems (Supporting Information S7) were first normalized 200 by the response in the abiotic controls measured within the same analytical series, and then 201 plotted as a function of incubation time. GraphPad Prism 5.00 was used to fit a first order 202 degradation model with lag phase (excluded for chemicals partly degraded after one day) to the 203 data. $95 \%$ confidence limits were estimated by substituting $k_{\text {system }}$ for $10^{\wedge}\left(\log \left(k_{\text {system }}\right)\right)$ and 204 treating $\log \left(k_{s y s t e m}\right)$ as the variable, since degradation rate constants are constrained to positive 205 values and lognormal distribution of biodegradation rate constants were seen for hydrocarbons in 206 a parallel study (data not included). In two test vials the response for 2,3-dimethylheptane and in 207 three test vials the response for 1,3,5-trimethylcyclohexane were $>150 \%$ of the response in the 208 abiotic controls. These five data points (of a total of $\sim 300$ datapoints) were removed as outliers. 209 This correction resulted in $<15 \%$ change in the fitted degradation rate constant (See Supporting 210 Information S4). In order to illustrate that the approach works equally well for both types of 211 models, a logistic model was also fitted to the data (see equations in Supporting information S1 212 and discussion in S5). $a_{\text {water }}$ and $k_{\text {water }}$ were calculated from $a_{\text {system }}$ and $k_{\text {system }}$ using equation 4 and 2135. 
214 In the phase distribution experiment, the distribution between headspace and water phase was 215 described by equation 6.

216 (6) $\frac{m_{w}}{m_{T}}=\frac{C_{w}}{C_{s t o c k}}=\frac{1}{1+K_{a w} \frac{V_{h}}{V_{w}}}$

217 Where $C_{\text {stock }}$ is the concentration of the test chemicals in the stock solution. GraphPad Prism was

218 used to plot $C_{w} / C_{\text {stock }}$ against $V_{h} / V_{w}$, fit equation 6 to the data and estimate $K_{a w} .95 \%$ confidence

219 limits of $K_{a w}$ were estimated using lognormal transformation of $K_{a w}$ as described above. The

220 quality criteria, $\mathrm{R}^{2}>0.8$, was used for the measured $K_{a w}$.

\section{Results and discussion}

223 The measured air water partition ratios for the five test chemicals meeting the quality criteria 224 were in the same order of magnitude as literature data (Table 1). 
Table 1: Measured air water partition ratio with $95 \%$ confidence limits in brackets and literature 227 values. The values used for calculations in the manuscript indicated in bold, predicted values 228 indicated in italic.

\begin{tabular}{l|ccc}
\hline Compound & $\begin{array}{c}\text { Measured } K_{a w} \\
(L / L)\end{array}$ & $R^{2}$ & $\begin{array}{c}\text { Literature } K_{a w}(L / L) \text { at } \\
25^{\circ} \mathrm{C}\end{array}$ \\
\hline Bicyclohexyl & $\mathrm{ND}^{\mathrm{a}}$ & & $\mathbf{4}^{\mathrm{b}}$ \\
Biphenyl & $\mathrm{ND}^{\mathrm{a}}$ & & $\mathbf{0 . 0 1 3}^{\mathrm{c}} ; 0.005-0.17^{\mathrm{d}}$ \\
Decalin & $\mathbf{1 4}(12-16)$ & 0.96 & $19^{\mathrm{b}} ; 4.8^{\mathrm{e}}$ \\
$n$-Decane & $\mathrm{ND}^{\mathrm{a}}$ & & $\mathbf{2 1 0} ; 130-280^{\mathrm{d}}$ \\
2,3-Dimethylheptane & $\mathbf{3 1}(25-37)$ & 0.88 & $17 ; 281 ; 163^{\mathrm{f}}$ \\
Naphthalene & $\mathrm{ND}^{\mathrm{a}}$ & & $0.006^{\mathrm{g}} ; \mathbf{0 . 0 1 8}^{\mathrm{c}}-0.030^{\mathrm{d}}$ \\
Tetralin & $\mathbf{0 . 0 4 9}(0.034-0.056)$ & 0.83 & $0.056^{\mathrm{b}} ; 0.076^{\mathrm{e}}$ \\
$1,2,4-$-Trimethylbenzene & $\mathbf{0 . 1 5}(0.13-0.19)$ & 0.93 & $0.25^{\mathrm{h}}$ \\
$1,3,5$-Trimethylcyclohexane & $\mathbf{3 3}(28-38)$ & 0.93 & $39 ; 24 ; 11^{\mathrm{f}}$ \\
\hline
\end{tabular}

${ }^{a}$ ND Not determined as $\mathrm{R}^{2}$ was less than 0.8. ${ }^{\mathrm{b}}$ (from National Food Institute DTU, 2015) ${ }^{\mathrm{c}}$ (Shiu 230 and Mackay, 1997) ${ }^{\mathrm{d}}$ (Mackay et al., 2006) ${ }^{\mathrm{e}}$ (Ashworth et al., 1988) ${ }^{\mathrm{f}}$ QSAR estimates from 231 EPISuite using the vapor pressure/water solubility method, Group method and Bond method 232 respectively (from National Food Institute DTU, 2015) ${ }^{\mathrm{g}}$ (Lee et al., 2012) ${ }^{\mathrm{h}}$ (Sanemasa et al., 233 1982).

235 In Table 2, the best fit for the lag phases, first order rate constants and logistic rate constants 236 are shown. Most of the chemicals showed a fast degradation after the lag phase, as illustrated in 237 Figure 1. 
240 Table 2: Lag phase, $t_{\text {lag }}$, test system first order degradation rate constants, $k_{\text {system }}$, water phase

241 first order rate constants, $k_{\text {water }}$, test system logistic degradation rate constants, $a_{\text {system }}$, water phase

242 logistic rate constants, $a_{\text {water }}$, and conversion factor, $k_{\text {water }} / k_{\text {system }}$, between test system and water

243 phase rate constants. $95 \%$ confidence intervals are indicated in brackets.

\begin{tabular}{|c|c|c|c|c|c|c|}
\hline & $\begin{array}{l}t_{\text {lag }} \\
{[\mathrm{d}]}\end{array}$ & $\begin{array}{l}k_{\text {system }} \\
{\left[\mathrm{d}^{-1}\right]}\end{array}$ & $\begin{array}{l}k_{\text {water }} \\
{\left[\mathrm{d}^{-1}\right]}\end{array}$ & $\begin{array}{c}a_{\text {system }} \\
{\left[\mathrm{d}^{-1} \%{ }^{-1}\right]}\end{array}$ & $\begin{array}{c}a_{\text {water }} \\
{\left[\mathrm{d}^{-1} \%{ }^{-1}\right]}\end{array}$ & $\begin{array}{c}k_{\text {water }} \\
/ k_{\text {system }}\end{array}$ \\
\hline Bicyclohexyl & $<1$ & $\begin{array}{c}0.28 \\
(0.25-0.32)\end{array}$ & 0.65 & $\begin{array}{c}0.002 \\
(0.0008-0.006)\end{array}$ & 0.005 & 2.3 \\
\hline Biphenyl & $\begin{array}{c}5.4 \\
(5.1-5.6)\end{array}$ & $\begin{array}{c}0.8 \\
(0.5-1.4)\end{array}$ & 0.8 & $\begin{array}{c}0.017 \\
(0.010-0.030)\end{array}$ & 0.017 & 1.0 \\
\hline Decalin & $\begin{array}{c}5.7 \\
(4.9-6.6)\end{array}$ & $\begin{array}{c}0.23 \\
(0.16-0.33)\end{array}$ & 1.3 & $\begin{array}{c}0.009 \\
(0.006-0.013)\end{array}$ & 0.051 & 5.7 \\
\hline n-Decane & $<1$ & $\begin{array}{c}1.4 \\
(1.1-1.8)\end{array}$ & 96 & $\begin{array}{c}0.02 \\
(0.007-0.06)\end{array}$ & 1.5 & 71 \\
\hline $\begin{array}{l}2,3- \\
\text { Dimethylheptane }\end{array}$ & $\begin{array}{c}5.6 \\
(4.5-6.6)\end{array}$ & $\begin{array}{c}0.5 \\
(0.3-0.9)\end{array}$ & 6 & $\begin{array}{c}0.020 \\
(0.016-0.025)\end{array}$ & 0.22 & 11 \\
\hline Naphthalene & $\begin{array}{c}5.8 \\
(5.7-6.0)\end{array}$ & $\begin{array}{c}1.1 \\
(0.7-1.7)\end{array}$ & 1.1 & $\begin{array}{c}0.020 \\
(0.015-0.027)\end{array}$ & 0.020 & 1.0 \\
\hline Tetralin & $\begin{array}{c}7.7 \\
(7.5-8.0)\end{array}$ & $\begin{array}{c}0.8 \\
(0.5-1.4)\end{array}$ & 0.8 & $\begin{array}{c}0.015 \\
(0.010-0.023)\end{array}$ & 0.015 & 1.0 \\
\hline $\begin{array}{l}1,2,4- \\
\text { Trimethylbenzene }\end{array}$ & $\begin{array}{c}5.5 \\
(5.2-5.8)\end{array}$ & $\begin{array}{c}0.42 \\
(0.31-0.58)\end{array}$ & 0.44 & $\begin{array}{c}0.013 \\
(0.008-0.019)\end{array}$ & 0.013 & 1.1 \\
\hline $\begin{array}{l}\text { 1,3,5-Trimethyl- } \\
\text { cyclohexane }\end{array}$ & \multicolumn{6}{|c|}{ No Biodegradation } \\
\hline
\end{tabular}




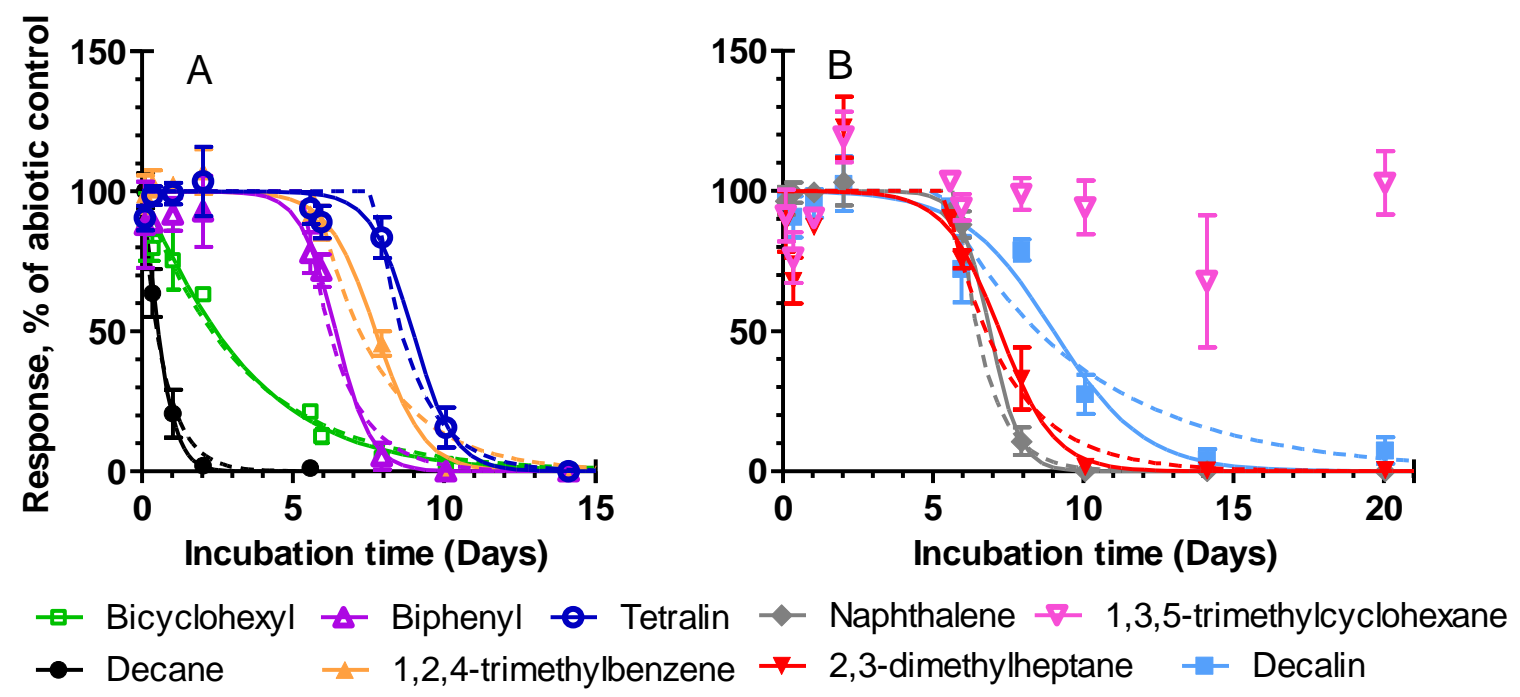

246 Figure 1. Degradation data for the test chemicals (A and B) with standard error on mean $(n=3)$

247 and fitted degradation curves using the logistic model (full line) and the first order model 248 including lag phase (broken line).

250 The conversion factor, $k_{\text {water }} / k_{\text {system }}\left(=a_{\text {water }} / a_{\text {system }}\right)$, (see Table 2$)$ can be viewed as the factor by 251 which degradation rates are underestimated if headspace is not considered for volatile chemicals, 252 and demonstrate the degree of conservatism currently applied to results of biodegradation tests.

253 The conservatism is not only applied to volatile chemicals, but also to hydrophobic chemicals 254 when sorbed to the test vessel, sorbed to suspended matter or partly undissolved. For a correction 255 to be appropriate, some requirements need to be fulfilled. First of all, the approach requires that 256 the transfer between the headspace and the water phase is faster than the degradation in order to 257 maintain equilibrium in the test system. Secondly, the correction should be larger than the 258 uncertainty of the original value and thirdly, the correction factor should have a reasonably low 259 uncertainty. In stirred or agitated systems, the phase transfer is expected to be fast compared to 
260 the biodegradation. For the test chemicals with an air water partition ratio $<0.4 \mathrm{~L} / \mathrm{L}$ (or Henry's 261 laws constant $<10^{-2}$ atm m $3 / \mathrm{mol}$ or $10^{3} \mathrm{~Pa} \mathrm{~m}^{3} / \mathrm{mol}$ ), the calculated $k_{\text {water }}$ and $a_{\text {water }}$ were within

262 the $95 \%$ confidence intervals of $k_{s y s t e m}$ and $a_{s y s t e m}$, respectively, and these chemicals did therefore 263 not require attention to the distribution in the test system. For the test chemicals with an air water 264 partition ratio $\geq 4 \mathrm{~L} / \mathrm{L}$ (or Henry's laws constant $>10^{-1}$ atm m $3 / \mathrm{mol}^{3}$ or $10^{4} \mathrm{~Pa} \mathrm{~m}^{3} / \mathrm{mol}$ ) the water 265 phase rate constants were significantly higher than the test system rate constants. For two of 266 these chemicals the distribution in the test system could be determined relatively precisely, and 267 for these chemicals the correction therefore improves the determination of the degradation rate 268 constant. For decalin the first order degradation rate constant corresponded to a half-life of 3 269 days in the test system and 0.5 days in the water phase.

270 Decane has a very high volatility from water, and determination of reliable air to water 271 partition ratios are a challenge and has yielded highly varying results (Sedlbauer et al., 2002). 272 The conversion factor (72) for decane should therefore be treated with care. The rates 273 corresponded to a half-life of 0.5 days in the test system and a half-life of 10 minutes in the water 274 phase. These data indicate that the degradation is so fast that it can compete with volatilization 275 processes in the environment. However, until more reliable measurements of the air water 276 partitioning are produced, the results for decane are subjected to a large uncertainty.

277 There are different aims and reasons for doing biodegradation tests. It may be argued that a 278 correction should not be done in order to keep the estimate conservative for regulatory purposes. 279 However, we find it unreasonable to apply conservatism that applies selectively to certain types 280 of chemicals (in this case volatile chemicals). Furthermore test results are not only used in a 281 regulatory context. Comparison of biodegradation kinetics between different biodegradation tests 282 is only appropriate based on headspace-corrected rate constants, and the corrected rate constants 
283 are better defined input parameters for aquatic exposure and fate models. It may also be argued

284 that the variation between degradation rate constants measured in water/inoculum from different

285 sites can be higher than the correction factors used here and correction is therefore not necessary.

286 However, since the correction affects most or all of the measurements, it shifts the complete 287 population of rate constants.

288 We here supply researchers, regulators and contract laboratories with an approach, easily 289 adoptable into the regulatory framework, to correct for artifact due to the difference between test 290 system and water phase degradation rates and suggest the use of this conversion method when 291 reporting degradation kinetics for chemicals with an air water partition ratio $\geq 4 \mathrm{~L} / \mathrm{L}$ (or Henry's 292 laws constant of $\sim 10^{-1} \mathrm{~atm} \mathrm{m^{3 }} / \mathrm{mol}$ or $10^{4} \mathrm{~Pa} \mathrm{~m}^{3} / \mathrm{mol}$ ). For chemicals with lower air water 293 partition ratio but higher hydrophobicity, the dominating process will be the partitioning between 294 water and suspended matter, sediment and dissolved organic matter or the dissolution from the 295 pure phase. The proposed framework of separating effective concentration and total mass for the 296 calculation of water phase degradation rates can then still be applied as long as degradation 297 rather than phase partitioning is rate limiting.

300 Supporting Information. Details of passive dosing format and analytical method, logistic 301 model equations, degradation data for 2,3-Dimethylheptane without outlier removal, comment 302 on model choice in relation to distribution conversion and fit of data from the phase distribution 303 test. This material is available free of charge. 
305 The authors thank Concawe for financial support and Hanne Bøggild for technical assistance in

306 the laboratory. 
REFERENCES

309 Adam, I.K.U., Rein, A., Miltner, A., Fulgêncio, A.C.D., Trapp, S., Kästner, M., 2014.

310 Experimental results and integrated modeling of bacterial growth on an insoluble

311 hydrophobic substrate (phenanthrene). Environ. Sci. Technol. 48, 8717-8726.

312 doi:10.1021/es500004z

313 Aronson, D., Boethling, R., Howard, P., Stiteler, W., 2006. Estimating biodegradation half-lives

314 for use in chemical screening. Chemosphere 63, 1953-1960.

315 doi:10.1016/j.chemosphere.2005.09.044

316 Ashworth, R.A., Howe, G.B., Mullins, M.E., Rogers, T.N., 1988. Air-Water Partitioning

317 Coefficients of Organics in Dilute Aqueous Solutions. J. Hazard. Mater. 18, 25-36.

318 Comber, M.I.H., den Haan, K.H., Djemel, N., Eadsforth, C.V., King, D., León Paumen, M.,

319 Parkerton, T., Dmytrasz, B., 2012. Primary Biodegradation of Petroleum Hydrocarbons in

320 Seawater. Concawe, Brussels. doi:ISBN 978-2-87567-012-0

321 European Parliament, 2006. Regulation (EC) No 1907/2006 of the European Parliament and of 322 the Council of 18 December 2006.

323 Gouin, T., Cousins, I., Mackay, D., 2004. Comparison of two methods for obtaining degradation 324 half-lives. Chemosphere 56, 531-5. doi:10.1016/j.chemosphere.2004.04.018

325 Guha, S., Jaffé, P.R., 1996. Determination of monod kinetic coefficients for volatile hydrophobic 326 organic compounds. Biotechnol. Bioeng. 50, 693-9. doi:10.1002/(SICI)1097327 0290(19960620)50:6<693::AID-BIT10>3.0.CO;2-G

328 Höhener, P., Duwig, C., Pasteris, G., Kaufmann, K., Dakhel, N., Harms, H., 2003. 
Biodegradation of petroleum hydrocarbon vapors: Laboratory studies on rates and kinetics in unsaturated alluvial sand. J. Contam. Hydrol. 66, 93-115. doi:10.1016/S01697722(03)00005-6

332

Howard, P., Meylan, W., Aronson, D., Stiteler, W., Tunkel, J., Comber, M., Parkerton, T.F., 2005. A new biodegradation prediction model specific to petroleum hydrocarbons. Environ. Toxicol. Chem. 24, 1847-1860. doi:10.1897/04-453R.1

Khan, A.M., Wick, L.Y., Harms, H., Thullner, M., 2016. Biodegradation of vapor-phase toluene in unsaturated porous media: Column experiments. Environ. Pollut. 211, 325-331. doi:10.1016/j.envpol.2016.01.013

Lee, H., Kim, H., Kwon, J., 2012. Determination of Henry's Law Constant Using Di ff usion in Air and Water Boundary Layers.

Mackay, D., Shiu, W.Y., Ma, K.-C., Lee, S.C., 2006. Handbook of Physical-Chemical Properties and Environmental Fate for Organic Chemicals, Second Edi. ed. CRC Press, Taylor \& Francis, London.

Mayer, P., Vaes, W.H.J., Hermens, J.L.M., Oomen, A.G., Tolls, J., 2000. Absorption of hydrophobic compounds into the poly(dimethylsiloxane) coating of solid-phase microextraction fibers: high partition coefficients and fluorescence microscopy images. Anal. Chem. 72, 459-64. doi:10.1021/ac990948f

National Food Institute DTU, 2015. EPISuite data accessed via Danish (Q)SAR Database. [WWW Document]. URL http://qsardb.food.dtu.dk/database/index.html (accessed 3.8.16).

OECD, 301, 1992. Test No. 301: Ready Biodegradability. OECD Guidel. Test. Chem. 1-62. 
doi:10.1787/9789264070349-en

351

352

353

354

355

356

357

358

359

360

361

362

363

364

365

366

367

368

369

370

OECD 309, 2004. OECD Guideline for the testing of Chemicals. Aerobic Mineralisation in Surface Water - Simulation Biodegradation Test. doi:10.1787/9789264070547-en

Ostendorf, D.W., Schoenberg, T.H., Hinlein, E.S., Long, S.C., 2007. Monod Kinetics for Aerobic Biodegradation of Petroleum Hydrocarbons in Unsaturated Soil Microcosms. Environmenal Sci. Technol. 41, 1-11.

Prince, R.C., Haitmanek, C., Lee, C.C., 2008. The primary aerobic biodegradation of biodiesel B20. Chemosphere 71, 1446-1451. doi:10.1016/j.chemosphere.2007.12.010

Prince, R.C., Parkerton, T., Lee, C., 2007. The primary aerobic biodegradation of gasoline $\begin{array}{llll}\text { hydrocarbons. } & \text { Environ. } & \text { Sci. } & \text { Technol. }\end{array}$ doi:10.1016/j.chemosphere.2007.12.010

Reichenberg, F., Mayer, P., 2006. Two complementary sides of bioavailability: accessibility and chemical activity of organic contaminants in sediments and soils. Environ. Toxicol. Chem. 25, 1239-1245. doi:10.1897/05-458R.1

Rein, A., Fernqvist, M.M., Mayer, P., Trapp, S., Bittens, M., Karlson, U.G., 2007. Degradation of PCB congeners by bacterial strains. Appl. Microbiol. Biotechnol. 77, 469-481. doi:10.1007/s00253-007-1175-6

Sanemasa, I., Araki, M., Deouchi, T., Nagai, H., 1982. Solubility Measurements of Benzene and the Alkylbenzenes in Water by Making Use of Solute Vapor. Bull. Chem. Soc. Japan 55, $1054-1062$.

Schirmer, M., Butler, B.J., Roy, J.W., Frind, E.O., Barker, J.F., 1999. A relative-least-squares 

technique to determine unique Monod kinetic parameters of BTEX compounds using batch experiments. J. Contam. Hydrol. 37, 69-86. doi:10.1016/S0169-7722(98)00159-4

373 Sedlbauer, J., Bergin, G., Majer, V., 2002. Group Contribution Method for Henry ' s Law 374 Constant of Aqueous Hydrocarbons. AlChE J. 48, 2936-2959.

375 Shiu, W.Y., Mackay, D., 1997. Henry’s Law Constants of Selected Aromatic Hydrocarbons, 376 Alcohols, and Ketones. J. Chem. Eng. Data 42, 27-30. doi:10.1021/je960218u

377 Simkins, S., Alexander, M., 1984. Models for mineralization kinetics with the variables of 378 substrate concentration and population density. Appl. Environ. Microbiol. 47, 1299-1306.

379 Sleep, B.E., Mulcahy, L.J., 1998. Estimation of Biokinetic Parameters for Unsaturated Soils. J. 380 Environ. Eng. 124, 959-969. doi:10.1061/(ASCE)0733-9372(1998)124:10(959)

381 US Public law, 2002. Toxic substances control act.

382 Woo, S.H., Park, J.M., Rittmann, B.E., 2001. Evaluation of the interaction between 383 biodegradation and sorption of phenanthrene in soil-slurry systems. Biotechnol. Bioeng. 73, $384 \quad 12-24$. 